\title{
Research on the Development Strategy of Logistics Firms in China
}

\author{
Lan Wang \\ International School of Business, Beijing Language and Culture University, Beijing, China \\ Email: im2003@163.com
}

Received June 2014

\begin{abstract}
The logistics industry has attracted wide attention as an important industry that supports economic development. Most of Chinese logistics enterprises are transferred from traditional transportation and warehousing business. Their information integration and mining capacity is insufficient. The basis of weak competitiveness of the traditional logistics industry needs to be improved. By analyzing the driven factors of modern logistics industry, the paper further discusses Chinese logistics enterprises' problems and analyzes the case of $X$ company to describe the business strategy of modern logistics firms.
\end{abstract}

\section{Keywords}

Logistics Industry, Resource Integration, Distribution Structure, Value Added Service

\section{Introduction}

Based on the development prospects of logistics industry and its contribution to economic development, Chinese government is actively developing the logistics industry policies to effectively guide and promote the competence of logistics industry. Currently, the logistics industry has attracted wide attention as an important industry that supports China's economic development. In the development process of China's logistics industry, whether professional logistics service providers can provide high level of service to meet the requirements of customers determines the future development trend of China's logistics industry [1].

Modern logistics industry is one of the critical industries to be developed in China's "Eleventh Five-Year Plan". The government introduced the "logistics industry restructuring plan". In the logistics industry restructuring plan, it is said that manufacturing and trade enterprises are encouraged to outsource logistics services in order to integrate logistics resources. Logistics industry is also very important to influence the competence of related industry. The government also encouraged the interaction between logistics, trading and manufacturing enterprises to achieve effective and efficient supply chain. From the logistics industry restructuring plan, it can be seen that to encourage the development of the logistics industry, to enhance the logistics service level, to promote joint development of the logistics enterprises and manufacturing enterprises is an important issue. Hence, to develop logistics industry in response to the call of national and local policy may have the priority to got support. 


\section{The Driven Factors of Modern Logistics Industry}

With the development of information technology and network-based economy, the competition among enterprises further increase; at the same time, great changes in political, economic and social environment lead to increasingly diverse needs and demand uncertainty. It is because of demand diversity and uncertainty of market demand, more companies need to constantly enhance their competence. Intensive competition in the global market promotes the development of logistics industry. The changes of the environment reflected in the following three aspects:

\subsection{Channel Structural}

The planned inventory policy can no longer meet current market needs. This operating system works in the previous market environment and can reasonably get good performance, because the manufacturers in the circulation system stay in a dominant position with the relatively limited products and services. Strong business bargaining power in manufactures determines the flow of business process and ways to meet the needs of the terminal customers. However, over the past few years, with the development of logistics industry and modern information technology, the downstream distribution terminals in direct contact with customers demand information appeared in a leap changes, thus changing the pattern of the original balance of power in the channel. This change reflected in the retailing industry. Buying and selling are in large quantities with the economy of scale, such as supermarkets, shopping malls, convenience stores, discount stores, etc. This change has transformed the channel structure from original manufacturers control to inter-firm vertical relationships and long-term partnerships. Interaction and cooperation between enterprises are needed in order to respond to the consumer market as soon as possible [2]. In addition, with structural changes in this circulation system, the retailer's position has changed and their role becomes more and more important. Retailer and wholesalers break some of the original business model and gradually use its original advantages of large-scale operations to become the professional logistics companies for the upstream and downstream enterprises to provide more services through its own highquality logistics services and information accumulation capacity. They, together with manufacturers and retailers improve operational efficiency and competitiveness of the industrial chain.

\subsection{Customer Demand}

Changes in customer demand also contribute to the development of modern logistics industry, namely the degree of uncertainty in consumer demand is constantly increased. Customers face the various types of products and services. Due to the competitive market environment, on the one hand, a small amount of multi-species mode of production is necessary, on the other hand in order to improve production efficiency, it must be timely and accurate understanding of the market to eliminate slow-moving merchandise. The enterprises need to accurately predict what type of products and how much to provide. The realization of all these production purposes is dependent on the coordination of sales, logistics, operations management. Obviously, in the traditional distribution channels the information sharing and collaboration is poor, now more collaborative activities are required between the production and marketing to adapt to market change. The entire process of information exchange required [2]. Totally depending on the manufacturer or retailers to achieve timely delivery is difficult. In order to enhance customer service, manufacturers and retailers must establish customer-oriented and efficient logistics service system, or use professional social logistics service system. Logistics management is no longer so subordinate to production activities. For the entire industrial chain, it is an important part.

\subsection{Industrial Integration and Formation of Business Networks}

The traditional boundaries of product or industry can not meet the fierce competition. A very important reason is technology and innovation factors. Companies can no longer rely on their own resources and capabilities to meet market demand, which led to the product line integration and inter-firm integration. While under the conditions of modern industrial integration, manufacturing enterprises not only need close cooperation but also among manufacturing enterprises and logistics, retail enterprises need to form a coordinated network for the end customers to provide highly specialized logistics or sales services, timely flow of the various stages of the product information and timely feedback to all participants on the operation of the network [3]. Obviously, this technology driven elements of the new operating system has completely broken the traditional marketing system. The 
traditional logistics enterprises transfer from warehousing and inventory functions as the leading system for controlling operation to the upstream and downstream cooperation between enterprises. It is no longer based on negotiations force determined by the size and the arm length transaction, but the urgent need to integrate information based on long-term partnership.

Therefore, A new model is required to enhance modern logistics production and management efficiency to overcome the flaws and shortcomings of the traditional distribution model The new logistics model is the operating system with the forecasting function corresponds to the actual needs of the customer as the center of the reactive mode of modern logistics development.

\section{The Importance of Logistics Service}

First, supply chain logistics service has become an important part of corporate differentiation strategy. For a long time, logistics has not attracted great attention due to consumer mass-marketing phase (Mass Marketing), since the business is established on the basis of economies of scale of mass production and a large number of sales. Therefore, the logistics function just stays in the supportive business activities. Logistics subordinate to the production and sales, thus becoming the subsidiary functions of the business activities of enterprises. However, in market segmentation period, the market demand is diversified and decentralized. In this situation, enterprises which rapidly and effectively meet their desires can survive and develop in the fierce competition and market changes Differentiated business strategy has differences on customer service. Logistics services as an important part of differentiated customer service accordingly has a strategic significance.

Second, the establishment of the logistics service level has a significant impact on business performance. Logistics service level is a prerequisite to build a logistics system. Logistics began to become an important part of business strategy process. Logistics services with increasing economic characteristics vary with changes in market mechanisms and price mechanism. In other words changes in the market mechanism and the price mechanism determines the value of logistics services and the cost of a certain standard of service. Logistics service supply is not unlimited, otherwise, excessive logistics is to damage business performance and the stability of corporate. Thus, the development of reasonable logistics service level is an important part of corporate strategic activities, especially for transportation, emergency delivery and other logistics services.

Third, Logistics services have significant effect to reduce the distribution cost. Low-cost strategy has always been an important part of corporate marketing tactics. Low-cost implementation often involves the whole process of commodity production and circulation. In addition to a variety of physical factors affecting the production of raw materials and labor costs, soft element like logistics service mode also has a considerable influence on costs. Logistics can not only improve the efficiency of the circulation of commodities, but also can enhance the profitability of the enterprises. It has become the third source of corporate profits. Consumer prices and costs mean a lot to the profit. Some large-scale retailers reduce the cost of commodity procurement and supply logistics by change the self-built logistics system and run the practice in favor of the implementation of the third party logistics, JIT distribution and other new logistics services to support the retail business strategy. Hence, decision-making of logistics services has become an integral and important business strategy.

Forth, the logistics service is an important means of linking suppliers, manufacturers, wholesalers and retailers. With the development of modern economic globalization and networking, the competition of modern enterprises is not competition between individual enterprises, but a network competition. Therefore, the structure of the business network is the main content of today's competitive strategy. Logistics services as a unique service, on the one hand, take the commodity as a medium, breaking the barriers between suppliers, manufacturers, wholesalers and retailers, effectively promote the flows of the entire process and generate the smooth flow from production to the end customer. On the other hand, logistics services with its own unique system facilities will continue to share information of goods to all enterprises in the entire circulation process. Through the accumulation of knowledge, know-how and management resources, continuous coordination of the corresponding changes in the market, thus create supply chain value beyond a single enterprise.

\section{China’s Modern Logistics Enterprises Problems}

\subsection{Information Integration Is Poor}

Considerable number of enterprises uses the traditional stock driven logic to meet customer needs. Suppliers can 
not accurately understand the end customer's specific needs and market trends and cannot understand all aspects of inventory, which make it difficult to make the rational decision-making. Obviously, this is a lack of information sharing and difficult to support agile manufacturing or flexible production. Information integration and mining capacity of Chinese logistics enterprise is insufficient. In the international development of modern logistics industry, Channel participants not only need to know the order information of upstream and downstream and also to understand end consumer demand, the various stages of goods movement and inventory in transit. The entire business process will be new and virtual supply plan [4], which helps to eliminate the uncertainties and changes in the environment.

\subsection{Single Service Function}

Most of Chinese logistics firms engaged in the traditional and low-end demand logistics, while cannot effectively provide new and high-end demand logistics services. The market has great potential for further development high-end logistics service [2]. The business activities of logistics enterprises generally fall into two categories: high-end and low-end logistics services. Basic logistics services include line transportation, transshipment, storage, distribution and handling and other services. High-end logistics services include value added processing such as packaging, sorting, assembly, logistics information management, system design and optimization services. These services help to optimize business processes and create customer value. Most of the logistics firms focused on a traditional single-function service (the storage or transportation). Very few firms are able to provide professional logistics information system design, the joint inter-firm planning, collaborative inventory management, integrated solution services.

\subsection{Intensive Price Competition}

Many of Chinese logistics enterprises originally engaged in the traditional storage and transportation business. The existing warehousing and transportation firms are part of the potential competitors. To some extent, they can provide similar services. Therefore price competition in traditional logistics service is fierce. The current logistics market entry barriers in China are relatively low. This is one of the important factors that cause intensive and cut throat competition. Most small business entities with the limited assets and investment make the logistics market exit barriers are low. As the road toll, oil and other transportation costs rose sharply, the small and medium firms with low market performance exit the market. The other part of logistics firms enrich the service content and become modern logistics enterprises. Logistics enterprises get their competitive position through price wars, advertising wars, the introduction of new services strategy and tactics. Meanwhile foreign logistics companies pose a threat to existing logistics companies. Foreign logistics enterprises enter into the domestic logistics market, therefore, the logistics enterprises need to improve their competitiveness by improving service levels, using modern facilities, equipment and technology to enhance core business, expand the customer base and establish their brand [5].

\section{X Company's Business Model and Development Strategy Analysis}

$\mathrm{X}$ is a global leader in equipment maintenance, repair and operations industrial distributor with 80 years history. In 2008, the sales revenue of $X$ company has reached $\$ 6.9$ billion with more than 600 stores worldwide, 18 distribution centers and extensive sales network to provide more than 900,000 wide range of industrial products to more than 2 million customers in 150 countries from more than 3000 suppliers. The objective of $\mathrm{X}$ company is to guarantee the normal operation of their facilities and reduce customer acquisition costs. $\mathrm{X}$ has more than 18,000 talented employees. Among the "Fortune" 500, it was conferred by the "Fortune" magazine as one of the most respected enterprises. Currently, $\mathrm{X}$ with a distribution pattern of specialization and leading technology entered into China in September 2006.

X provides “one-stop” MRO products. With the complete line of MRO products (electrical and lighting, tools, and analytical instruments, pumps and fittings, material handling, safety and security, metal processing, welding and plant parts, refrigeration, heating, ventilation and air conditioning equipment, etc.) and adequate stock, in China for the majority of customers, $\mathrm{X}$ provide professional services to MRO procurement to save time and costs for customers. $\mathrm{X}$ has a comprehensive and diversified product portfolio, across 15 product lines, more than 50,000 kinds of famous brands. 
X's customer base is the industrial manufacturing enterprises. Products focus on the daily consumption of machinery and equipment, raw materials outside the daily consumables. Such products for the industrial enterprises are the rapid consumption of non-critical items. The procurement of such items is mainly to reduce transaction costs and simplify the procurement process. Based on this, X established "warehouse plus office plus sales" model in order to achieve product-oriented and provide one-stop business model to reduce inventory costs, save time, eliminate the cost of poor quality and create value for customers [6].

$\mathrm{X}$ successfully helped normal operation of the customer's facilities and reduce customer purchasing costs. This model requires companies to have a similar, relatively stable customer base and upstream suppliers. The firm should form a large enough scale to maintain the advantage in the price negotiations. The core element of this model is pursuit of "economies of scale".

X's core competences support its successful business model and achieve long-term stable development. First of all, $\mathrm{X}$ has a high reputation and high level of trust and reputation. A brand with high reputation will help $\mathrm{X}$ increase customer loyalty and attract new customers. $\mathrm{X}$ also has rich supplier resources with international and domestic brand to provide main product. Customer network development from high end to low-end customers ensures corporate purchasing and supply scale. Secondly, X has mature operation system with the information technology and well-trained sales team. A group of professional procurement engineers and sales engineers ensure the implementation of efficient operation and management. Efficient operations and large scale procurement and supply model ensure X company to achieve low cost. Effective supplier relationship management ensure quality of its products. Hence, low-cost, large-scale, high-quality are the main competences.

Though analyzing X's internal core competence and characteristics of competition in the industry, we find X has a broad customer demand. Because $\mathrm{X}$ insists in a particular business domain, $\mathrm{X}$ has strong professional ability and low operational risk compared with its competitors. However, the potential disadvantage is that the business model and rapid responsiveness generated a lot of capital investment. In addition, the price of the products is relatively transparent, so the profit margin is limited. Also, such a business model experience threat of other integrated logistics. With strong product substitutability, low switching costs lead new entrants not very difficult to imitate. Private and state-owned enterprises may consider about the cost and original purchasing relationship. This may restrict X's competitive advantage.

\section{Acknowledgements}

This research is supported by Beijing supporting Central University joint project—Young Talent Plan (Project No. YETP0880).

\section{References}

[1] Song, H. and Wang, L. (2014) Strategic Purchasing Management in Supply Chain Management Environment. Beijing Jiaotong University Press, Beijing. (in Chinese)

[2] Lambert, D.M. and Cooper, M.C. (2000) Issues in Supply Chain Management. Industrial Marketing Management, 29, 65-83. http://dx.doi.org/10.1016/S0019-8501(99)00113-3

[3] Tachizawa, E.M. and Thomsen, C.G. (2007). Drivers and Sources of Supply Flexibility: An Exploratory Study. International Journals of Operations and Production Management, 27, 1115-1136. http://dx.doi.org/10.1108/01443570710820657

[4] Lambert, D.M., Cooper, M.C. and Pagh, J.D. (1998) Supply Chain Management: implementation Issues and Research Opportunities. International Journal of Logistics Management, 9, 1-19. http://dx.doi.org/10.1108/09574099810805807

[5] Dyer, J.H. and Singh, H. (1998) The Relational View: Cooperative Strategy and Sources of Inter-Organizational Competitive Advantage. Academy of Management Review, 23, 660-679.

[6] Langley, C.J. and Holcomb, M.C. (1992). Creating Logistics Customer Value. Journal of Business Logistics, 13, 1-27. 